\title{
Recovery of Acrylic Acid Using Calcium Peroxide Nanoparticles: Synthesis, Characterisation, Batch Study, Equilibrium, and Kinetics
}

\author{
B. S. De, ${ }^{a}$ K. L. Wasewar, ${ }^{a,{ }^{*}}$ V. R. Dhongde, ${ }^{a}$ S. S. Madan, ${ }^{a}$ and A. V. Gomase ${ }^{b}$ \\ ${ }^{a}$ Advanced Separation and Analytical Laboratory (ASAL), \\ Department of Chemical Engineering, \\ Visvesvaraya National Institute of Technology (VNIT), \\ Nagpur (M.S) 440010, India \\ ${ }^{b}$ Department of Fibres and Textile Processing Technology, Institute \\ of Chemical Engineering (ICT), Mumbai (M.S) 400019, India \\ doi: 10.15255/CABEQ.2016.1055b \\ Original scientific paper \\ Received: December 14, 2016 \\ Accepted: February 6, 2018
}

\begin{abstract}
Recovery of acrylic acid from aqueous solution using low-cost $\mathrm{CaO}_{2}$ nanoparticles was investigated. $\mathrm{CaO}$, nanoparticles were synthesized by co-precipitation technique and characterised using XRD and FTIR. A mechanism was proposed for adsorption of acrylic acid onto $\mathrm{CaO}_{2}$ nanoparticles based on FTIR analysis. Acrylic acid recovery is highly dependent on contact time, $\mathrm{CaO}_{2}$ nanoparticle dosage, initial acrylic concentration, and temperature. Langmuir, Freundlich, Dubinin-Radushkevich, Tempkin, Hill, Redlich-Peterson, Sips and Toth isotherms were used and well represented by Redlich-Peterson isotherm $\left(R^{2}=0.9998\right)$ as compared to other isotherms. Kinetic studies revealed pseudo-second-order kinetics $\left(k_{2}=1.962 \cdot 10^{-4} \mathrm{~g} \mathrm{mg}^{-1} \mathrm{~min}^{-1}\right)$ for adsorption of acrylic acid onto $\mathrm{CaO}_{2}$ nanoparticles. $\mathrm{CaO}_{2}$ nanoparticles exhibited high acrylic acid recovery over varied concentration ranges. The acrylic acid can be regenerated by desorption from the surface of adsorbent and utilised for numerous applications. The presented results may be useful for the design of adsorption system using nanoparticles, which can be extended to other systems.
\end{abstract}

Keywords:

acrylic acid, adsorption, calcium peroxide nanoparticles, equilibrium, kinetics, batch study

\section{Introduction}

Acrylic acid or vinyl formic acid $\left(\mathrm{CH}_{2}=\mathrm{CH}\right.$ $\mathrm{COOH}$ ) is an important organic acid for the manufacture of polymeric flocculants for water treatment, intermediates in the preparation of super-absorbent materials, adhesives and sealants, surface coatings, polishes, surfactants, plastic additives, dispersants, and textiles. ${ }^{1}$ The global market for acrylic acid is estimated to reach US\$20 billion in 2018, and its demand to reach 260 KTPA by $2020 .{ }^{2}$ The partial oxidation of propene, a single-step process, is the most commercial method for the production of acrylic acid, but the yield is at most $(50-60 \%)$, causing large amounts of waste. The two-step process achieves an overall yield of $90 \%$ via acrolein. ${ }^{3}$

Several biotechnological processes for the production of acrylic acid have been developed, which provide an attractive alternative, but the high cost of the recovery step in the generation of the acid poses a major challenge in its commercialization. ${ }^{4}$ Conse-

"Corresponding author: k wasewar@rediffmail.com;

klwasewar@che.vnit.ac.in; dr.kailaswasewar@gmail.com quently, it is essential to develop a simple and cost-effective method for the recovery of acrylic acid. Many studies have been conducted in respect of recovery of carboxylic acids from waste stream/ dilute solution. Hybrid and intensified separation processes, such as reactive distillation, extractive distillation, pervaporation and reactive distillation have been proven to be effective for the recovery of carboxylic acids. ${ }^{5-9}$ Adsorption has been proven to be an efficient technique to remove various compounds. ${ }^{10-26}$ Also, carboxylic acids can be recovered by adsorption. ${ }^{27-36}$ The literature on the removal of a few carboxylic acids from aqueous solutions by adsorption is summarised in Table 1, but limited work on the adsorption of acrylic acid from aqueous streams is available.

The selection of proper adsorbent having sufficient selectivity and capacity is the key to successful recovery/removal. A large specific area is of great significance for the adsorbents, which is attained by manufacturing techniques that result in solids with a microporous structure. Consequently, researchers have a growing interest to develop a novel cost-effective adsorbent with high adsorptive 
Table 1 - Summary of a few studies conducted on carboxylic acid adsorption

\begin{tabular}{|c|c|c|}
\hline Carboxylic acid & Adsorbent & Type of study \\
\hline $\begin{array}{l}\text { Oxalic acid, malonic } \\
\text { acid, succinic acid, gallic } \\
\text { acid, EDTA, TTHA }\end{array}$ & Titanium dioxide & Kinetic \\
\hline $\begin{array}{l}\text { Acetic acid, propionic } \\
\text { acid, butyric } \text { acid }^{31}\end{array}$ & $\begin{array}{l}\text { Activated carbon } \\
\text { from watermelon } \\
\text { shells }\end{array}$ & Equilibrium \\
\hline $\begin{array}{l}\text { Formic acid, acetic acid, } \\
\text { propionic } \text { acid }^{32}\end{array}$ & $\alpha-\mathrm{Al}_{2} \mathrm{O}_{3}$ & Kinetic \\
\hline $\begin{array}{l}\text { Acetic, citric, lactic, } \\
\text { and tartaric acids }{ }^{27}\end{array}$ & Hydrogels & Equilibrium \\
\hline $\begin{array}{l}\text { Glycolic acid and } \\
\text { acetic acid }\end{array}$ & AmberliteIRA-67 & Equilibrium \\
\hline$\alpha$-Toluic acid ${ }^{29}$ & $\begin{array}{l}\mathrm{CaO}_{2} \\
\text { nanoparticles }\end{array}$ & $\begin{array}{l}\text { Equilibrium, } \\
\text { kinetic thermo- } \\
\text { dynamic }\end{array}$ \\
\hline
\end{tabular}

capacity. Nanotechnology offers new promises in recent years. Nanoparticles possess distinct physical and chemical properties, and they may exhibit totally new characteristics as compared to their bulk form due to their high surface-to-volume ratio, and because of their small size, quantum effects come into play. ${ }^{37}$

Calcium peroxide $\left(\mathrm{CaO}_{2}\right)$ has proven its effectiveness in enhanced bioremediation of BTEX (benzene, toluene, ethylbenzene and xylene) contaminated soil ${ }^{38}$ and its use has also increased the remediation of soil. ${ }^{39}$ It has been used to provide oxygen for contaminant biodegradation in saturated soil, but studies have revealed that rate of oxidation reaction between calcium peroxide and contaminant is extremely slow. ${ }^{40}$ Therefore, to overcome this problem, nanosized $\mathrm{CaO}_{2}$ can be used, which can increase the surface-to-volume ratio and the rate of reaction.

In this study, the candidacy of synthesised $\mathrm{CaO}_{2}$ nanoparticles as an effective adsorbent for the recovery of acrylic acid from the aqueous stream has been studied. The effect of contact time, initial concentration, adsorbent dosage, and temperature on adsorption capacity was investigated by conducting batch experiments. Consequently, equilibrium isotherm and kinetics were also evaluated to design a batch adsorption system for the recovery of acrylic acid from aqueous stream.

\section{Materials and methods}

\section{Reagents}

Polyethylene glycol (PEG 200), ammonia solution $\left(\mathrm{NH}_{3} \cdot \mathrm{H}_{2} \mathrm{O}, 25 \%\right)$, calcium chloride $\left(\mathrm{CaCl}_{2}\right.$, $99.5 \%)$, hydrogen peroxide $\left(\mathrm{H}_{2} \mathrm{O}_{2}, 35 \%\right)$, sodium hydroxide $(\mathrm{NaOH})$ were supplied by Merck (India) and used without further treatment or purification. Acrylic acid (99\%) was obtained from S D FineChem Ltd. The stock solutions of acrylic acid (7206 $\mathrm{mg} \mathrm{L}^{-1}$ ) were prepared fresh every week by dilution of $7 \pm 0.1 \mathrm{~mL}$ of acrylic acid with double distilled water, and to obtain working solutions of varying concentrations for further experiments.

\section{Preparation of $\mathrm{CaO}_{2}$ nanoparticles}

$\mathrm{CaO}_{2}$ nanoparticles were synthesised using a slightly modified co-precipitation technique. ${ }^{41,42}$ In the present case, six grams of $\mathrm{CaCl}_{2}$ was dissolved in $60 \mathrm{~mL}$ distilled water along with $30 \mathrm{~mL}$ ammonia solution $(1 \mathrm{M})$ and $240 \mathrm{~mL}$ PEG 200 in a $1000-\mathrm{mL}$ beaker. PEG 200 was used as a surface modifier, which is important for obtaining nanoparticles as it provides steric stabilization by the formation of micelles. The solution was stirred at a constant rate with the continuous addition of $30 \mathrm{~mL} \mathrm{H}_{2} \mathrm{O}_{2}(30 \%)$ at a rate of three drops per minute. A clear and colourless to yellowish solution was obtained after 3 hours of stirring. To precipitate the product, $\mathrm{NaOH}$ solution ( $\mathrm{pH} 13$ ) was added slowly until $\mathrm{pH} 11.5$ was obtained and the mixture changed to a white suspension. The precipitate was separated by centrifugation at 10000 RPM and the white powder obtained was washed three times with $0.1 \mathrm{M} \mathrm{NaOH}$ solution, followed by washing with distilled water until $\mathrm{pH}$ of 8.4 for the residue water was achieved. The obtained precipitate was then dried in an evacuated oven for 2 hours at $353.15 \mathrm{~K}$ to obtain $\mathrm{CaO}_{2}$ nanoparticles. A vacuum oven was used to avoid contamination and prevent excess oxygen from coming in contact while drying, which may result in formation of $\mathrm{CaO}$ instead of $\mathrm{CaO}_{2}$. A vacuum oven also allows drying of nanoparticles at much lower temperature. A schematic representation of the process is presented in Fig. 1. The reactions involved in the synthesis of $\mathrm{CaO}_{2}$ nanoparticles by co-precipitation method are:

$$
\begin{gathered}
\mathrm{CaCl}_{2}+\mathrm{H}_{2} \mathrm{O}_{2} \rightarrow \mathrm{CaO}_{2}(\text { Hydrate })+2 \mathrm{HCl} \\
2 \mathrm{HCl}+2 \mathrm{NH}_{3} \rightarrow 2 \mathrm{NH}_{4} \mathrm{Cl}
\end{gathered}
$$

\section{Batch adsorption studies}

Adsorption experiments were conducted to study the effect of initial concentration of acrylic acid (720-7206 $\left.\mathrm{mg} \mathrm{L}^{-1}\right)$, contact time (5-200 min), adsorbent dosage $(0.01-0.1 \mathrm{~g}$ per $10 \mathrm{~mL})$, and temperature $(300.15-313.15 \mathrm{~K})$ on the removal efficiency of acrylic acid. The experiments were carried out by taking $10 \mathrm{~mL}$ of acrylic acid of known concentration in a $100-\mathrm{mL}$ Erlenmeyer flask with a known adsorbent dosage. Orbital shaking incubator 


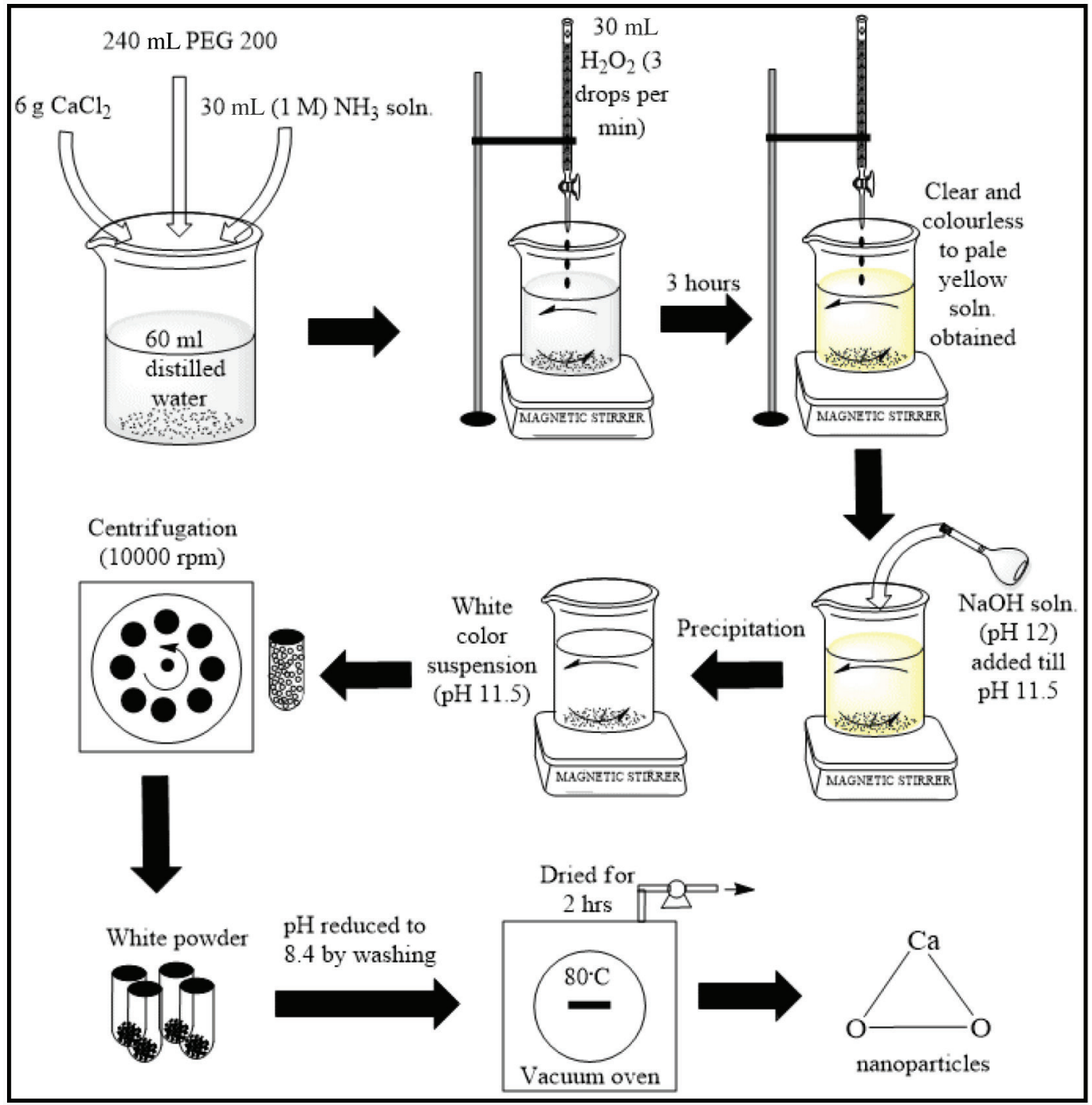

Fig. 1 - Schematic representation of the synthesis of $\mathrm{CaO}_{2}$ nanoparticles using co-precipitation technique

(REMI S-24BL, India) was employed to shake the mixture for a minimum of 200 minutes, and the samples were centrifuged at $3000 \mathrm{rpm}$ for 5 minutes after shaking to separate the spent $\mathrm{CaO}_{2}$ nanoparticles. The aqueous concentration of acrylic acid in the supernatant was determined by titration with $\mathrm{NaOH}(0.01 \mathrm{M})$ and phenolphthalein as an indicator. A fresh $\mathrm{NaOH}$ solution was prepared for each set of experiments. The concentration range of acrylic acid used in the study is based on highest concentration of acrylic acid that can be found in any aqueous stream. A few experiments were repeated and analysed, the consistency was observed within $\pm 2 \%$. The $\mathrm{pH}$ was measured by a digital $\mathrm{pH}$ meter (Spectral Lab Instrumental Pvt. Ltd. India) which was calibrated with three buffers $(\mathrm{pH} 4.0,7.0$ and 10.0) daily.

The removal efficiency, $E(\%)$, of acrylic acid was calculated as a ratio between acrylic acid adsorbed at time $t$, to its initial aqueous concentration as:

$$
E(\%)=\frac{C_{0}-C_{t}}{C_{0}} \cdot 100
$$

where, $C_{0}\left(\mathrm{mg} \mathrm{L}^{-1}\right)$ is the initial aqueous acrylic acid concentration, and $C_{t}\left(\mathrm{mg} \mathrm{L}^{-1}\right)$ is the aqueous acrylic acid concentration at time $t(\mathrm{~min})$.

The amount of acrylic acid adsorbed $\left(q \mathrm{mg} \mathrm{g}^{-1}\right)$ onto $\mathrm{CaO}_{2}$ nanoparticles at time $t$ was determined as:

$$
q_{t}=\frac{\left(C_{0}-C_{t}\right) \cdot V}{m}
$$

where, $m(\mathrm{~g})$ is mass of adsorbent, and $V(\mathrm{~L})$ is the volume of aqueous solution. The amount of acrylic acid adsorbed onto $\mathrm{CaO}$ nanoparticles at equilibrium $q_{e}$ is equal to $q$, while $C_{t}$ was addressed as $C_{e}$ at equilibrium time. A trial run was performed using conventional $\mathrm{CaO}_{2}$ at the start of experiment. The conventional $\mathrm{CaO}_{2}$ was observed to form lumps during adsorption, and the particles were not well 
dispersed even at longer shaking time. This lead to a low adsorption efficiency with the use of conventional $\mathrm{CaO}_{2}$. Also, a high dosage of $\mathrm{CaO}_{2}$ was required for effective acrylic acid recovery due to particle aggregation and large particle size.

\section{Desorption study}

A point study on desorption of acrylic acid from $\mathrm{CaO}_{2}$ nanoparticles was performed for the sample that showed highest level of adsorption. An ultrasonicator water bath (LABMAN LMUC-4) was employed for this purpose. $0.1 \mathrm{~g}$ spent $\mathrm{CaO}_{2}$ nanoparticles in $10 \mathrm{~mL}$ distilled water was taken in an Erlenmeyer flask at $333.15 \mathrm{~K}$. The sample was sonicated for 30 minutes and the aliquot of the resulting solution analysed by titration to determine the amount of desorbed acrylic acid.

\section{Results and discussion}

\section{Characterisation of $\mathrm{CaO}_{2}$ nanoparticles}

X-ray diffraction (XRD) analysis of $\mathrm{CaO}_{2}$ nanoparticles was carried out by X-ray diffractometer (PAN analytical X'pert PRO) in the $2 \theta$ range from $10^{\circ}$ to $100^{\circ}$ with a step size of $0.01^{\circ}$ using a $\mathrm{Cu}$ X-ray tube $(\lambda=0.15406 \mathrm{~nm})$ to ascertain the chemical composition (Fig. 2). The five dominant peaks of the XRD spectra at $2 \theta$ values of 29.68 , $36.19,47.74$, and 60.85 are in agreement with XRD of $\mathrm{CaO}_{2}$ (JCPDS - $\left.00-003-0865\right)$. The comparison of $2 \theta$ and $d$-spacing values of the standard $\mathrm{CaO}_{2}$ with the synthesised $\mathrm{CaO}_{2}$ nanoparticles are listed in Table 2, and the analogy confirms its chemical composition. The Debye-Scherrer equation was used to determine the average particle size of $\mathrm{CaO}_{2}$ nanoparticles from the XRD peak (110) pattern using the following expression:

$$
D=\frac{k \lambda}{\beta \cos \theta}
$$

Table 2 -Comparison of $2 \theta$ and $d$-spacing values of the standard $\mathrm{CaO}_{2}$ with the synthesised $\mathrm{CaO}_{2}$ nanoparticles

\begin{tabular}{c|c|c|c|c|c}
\hline \multirow{2}{*}{$\begin{array}{c}\text { Sr. } \\
\text { No. }\end{array}$} & \multicolumn{2}{|c|}{$\mathrm{CaO}_{2}$ (JCPDS - 00-003-0865) } & \multicolumn{2}{|c}{$\begin{array}{c}\text { Synthesised } \mathrm{CaO}_{2} \\
\text { nanoparticles }\end{array}$} \\
\cline { 2 - 6 } & $\begin{array}{c}2 \theta \\
(\text { degree })\end{array}$ & $\begin{array}{c}\text { d-spacing } \\
(\AA)\end{array}$ & $\begin{array}{c}\text { Miller } \\
\text { indices } \\
\text { (h k 1) }\end{array}$ & $\begin{array}{c}2 \theta \\
(\text { degree })\end{array}$ & $\begin{array}{c}d \text {-spacing } \\
(\AA)\end{array}$ \\
\hline 1 & 30.27 & 2.95 & 002 & 30.96 & 2.88 \\
2 & 35.59 & 2.52 & 110 & 35.74 & 2.50 \\
3 & 47.30 & 1.92 & 112 & 47.32 & 1.91 \\
4 & 51.59 & 1.77 & 200 & 51.00 & 1.78 \\
5 & 53.21 & 1.72 & 113 & 53.42 & 1.71 \\
\hline
\end{tabular}

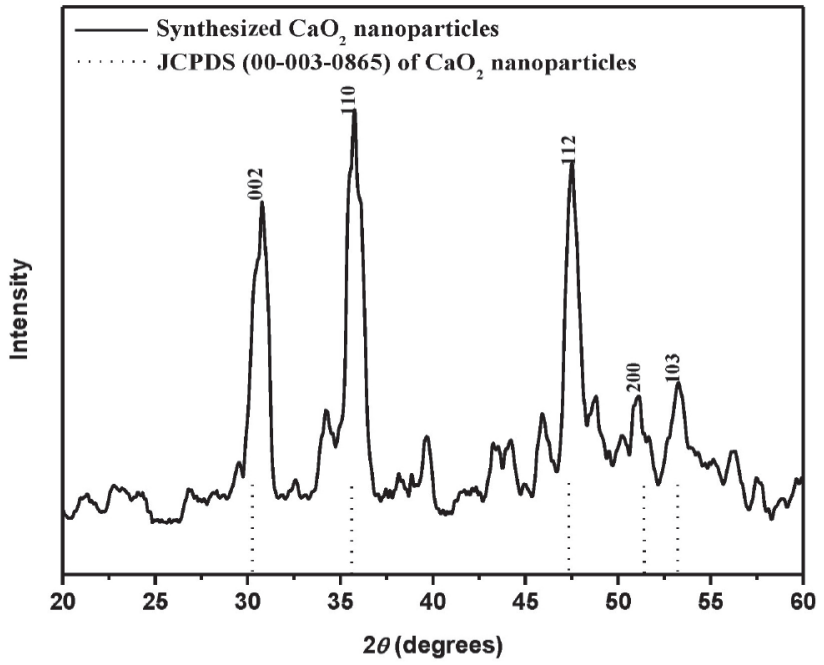

Fig. 2 -X-Ray diffraction pattern of synthesised $\mathrm{CaO}_{2}$ nanoparticles and standard JCPDS (000-03-0865) of $\mathrm{CaO}_{2}$ (dotted line)

where $k$ is the Debye-Scherrer constant $(k=0.9), \lambda$ is the wavelength of the incident $\mathrm{X}$-ray radiation $(\lambda=0.15406 \mathrm{~nm}), \theta$ is the Bragg's angle in radians, and $\beta$ is the full width at half maximum (FWHM) of the most intense peak (002). The calculated size of the nanocrystallite was found to be $29.38 \mathrm{~nm}$.

The Fourier Transfer Infrared (FTIR) spectrum of $\mathrm{CaO}_{2}$ nanoparticles, pure acrylic acid, and acrylic acid adsorbed onto $\mathrm{CaO}_{2}$ nanoparticles were obtained using Shimadzu Corporation IRAffinity-1 (Japan) apparatus within the range 4000 to $400 \mathrm{~cm}^{-1}$. Fig. 3 represents the plot of percent transmission versus wave number that was measured from FTIR. The spectra were analysed for different types of functional groups for the further confirmation of $\mathrm{CaO}_{2}$ nanoparticles and adsorption of acrylic acid onto $\mathrm{CaO}_{2}$ nanoparticles, thus suggesting a suitable mechanism for the adsorption process. The band positions present at 748 and $711 \mathrm{~cm}^{-1}$ correspond to $\mathrm{O}-\mathrm{O}$ stretch, and that of 560 and $508 \mathrm{~cm}^{-1}$ correspond to $\mathrm{O}-\mathrm{Ca}-\mathrm{O}$ stretch $^{43}$ for $\mathrm{CaO}_{2}$ nanoparticles (Fig. 3(a)). The spectrum of pure acrylic acid (Fig. 3(b)) shows a band at $1704 \mathrm{~cm}^{-1}$ which refers to $\mathrm{C}=\mathrm{O}$ stretch,${ }^{44}$ followed by bands at 1635,1243 , $1048,985,925,820$, and $650 \mathrm{~cm}^{-1}$ which correspond to $\mathrm{C}=\mathrm{C}$ stretch, $\mathrm{CH}$ in-plane bend, $\mathrm{CH}_{2}$ rocking, out of phase $\mathrm{CH}_{2}$ wag, and out-of-plane $\mathrm{CH}$ bend, out-of-plane $\mathrm{OH}$ bend, $\mathrm{CH}_{2}$ twist, and $\mathrm{CO}_{2}$ in-plane bend, respectively. ${ }^{41}$ The band that corresponds to $\mathrm{C}=\mathrm{O}$ stretch in the spectrum of pure acrylic acid is low in the spectrum of acrylic acid adsorbed onto $\mathrm{CaO}_{2}$ nanoparticles (Fig. 3(c)), which advocates the fact that $\mathrm{COO}$ group is chemically attached on the surface of $\mathrm{CaO}_{2}$ nanoparticles, thus proving the adsorption of acrylic acid onto $\mathrm{CaO}_{2}$ nanoparticles surface. It was also observed from the 


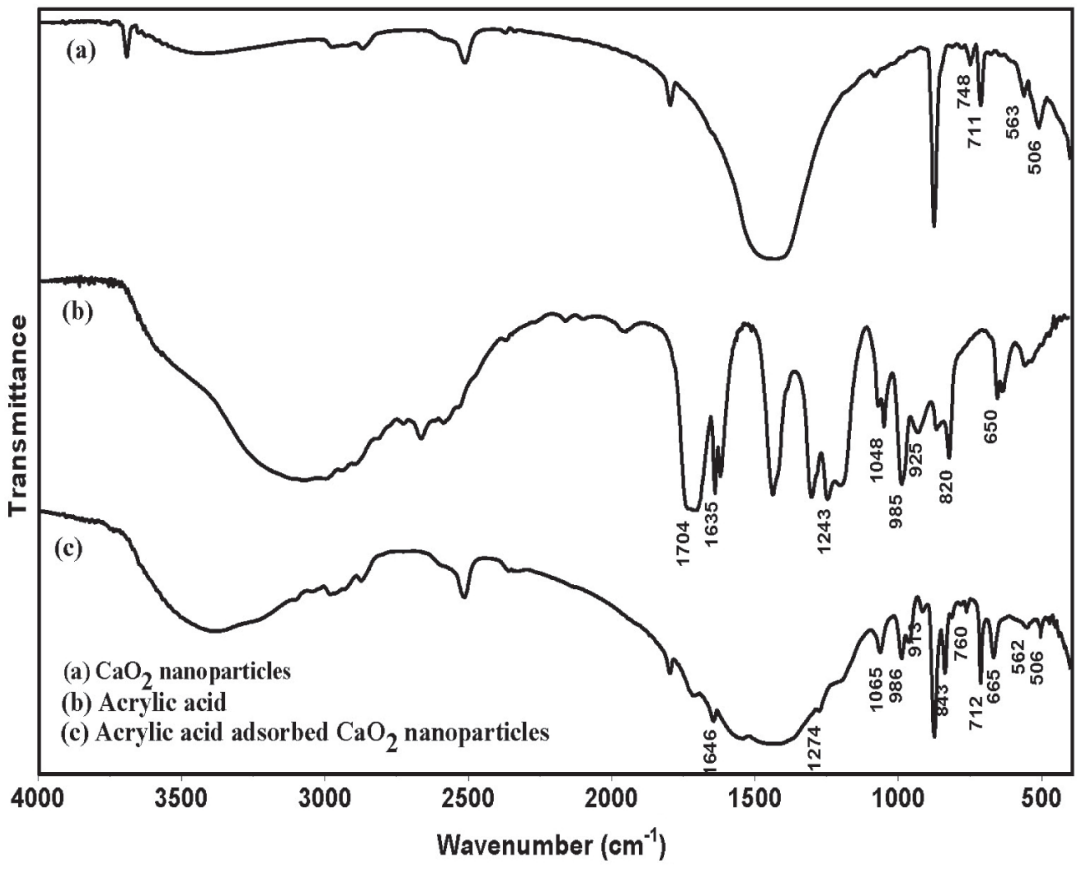

Fig. 3 - FTIR spectrum of (a) $\mathrm{CaO}_{2}$ nanoparticles, (b) acrylic acid, and (c) acrylic acid adsorbed $\mathrm{CaO}_{2}$ nanoparticles

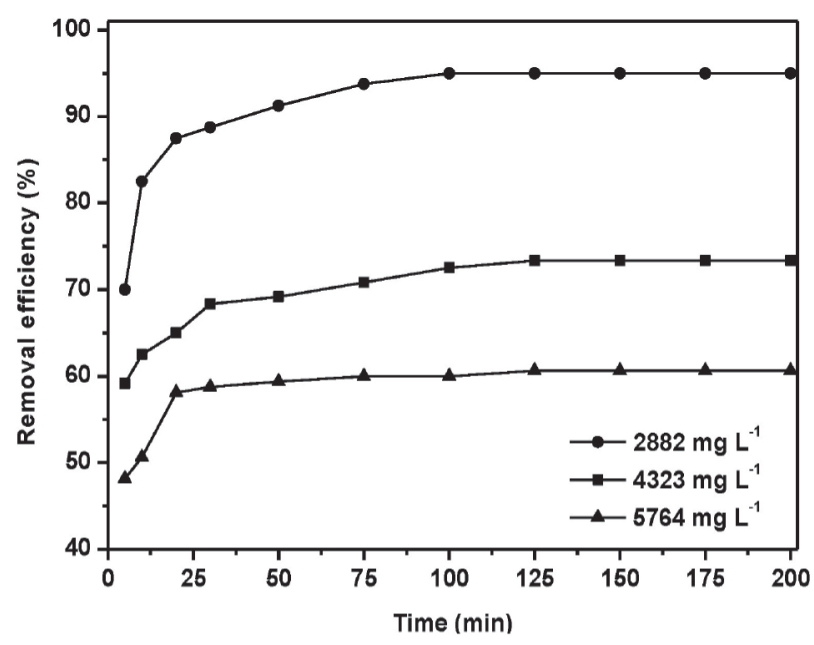

Fig. 4 - Effect of contact time on the removal efficiency of acrylic acid onto $\mathrm{CaO}_{2}$ nanoparticle (initial acrylic acid concentration $=2882,4323,5764 \mathrm{mg} \mathrm{L}^{-1}$, adsorbent dosage $=1 \mathrm{~g} \mathrm{~L}^{-1}$, temperature $=300.15 \mathrm{~K}$ )

spectrum of acrylic acid adsorbed onto $\mathrm{CaO}_{2}$ nanoparticles (Fig. 3(c)), that the bands at 1635, $1243,1048,985,925,820$, and $650 \mathrm{~cm}^{-1}$ that correspond to the acrylic acid spectrum (Fig. 3(b)), were shifted to $1646,1274,1065,986,913,843$, and 665 $\mathrm{cm}^{-1}$, respectively, after adsorption. Also, the bands at $760,712,560$, and $506 \mathrm{~cm}^{-1}$, in the case of acrylic acid adsorbed $\mathrm{CaO}_{2}$ nanoparticles, match the bands of $\mathrm{CaO}_{2}$ nanoparticles, signifying that the basic characteristics of $\mathrm{CaO}_{2}$ nanoparticles were retained even after the adsorption of acrylic acid.
Thus, it can be concluded from the comparison of FTIR spectra that acrylic acid adsorbs chemically onto the surface of $\mathrm{CaO}_{2}$ nanoparticles.

\section{Effect of contact time}

To investigate the effect of contact time on removal efficiency, experiments were conducted by varying the contact time from 5-200 minutes to ensure equilibrium for three different acrylic acid concentrations (2882, 4323, and $5764 \mathrm{mg} \mathrm{L}^{-1}$ ) with constant adsorbent dosage $\left(1 \mathrm{~g} \mathrm{~L}^{-1}\right)$ and temperature $(300.15 \pm 1 \mathrm{~K})$. The time required to reach equilibrium occurred relatively earlier in solutions containing lower acrylic acid concentrations than in those containing higher concentrations, which may be due to saturation of active sites available for adsorption (Fig. 4). The higher initial concentration of acrylic acid enhances the adsorption process and the increased adsorptive capacity of $\mathrm{CaO}_{2}$ nanoparticles due to higher concentration gradient. The initial rate of adsorption onto $\mathrm{CaO}_{2}$ nanoparticles was very fast, which corresponds to external surface adsorption, followed by the gradual adsorption stage, whose contribution to the total acrylic acid adsorption was relatively small. Finally, equilibrium was established within 125 minutes and was slightly dependent on initial acrylic acid concentration and considered as the optimum contact time for further studies.

\section{Effect of $\mathrm{CaO}_{2}$ nanoparticles dosage}

The effect of adsorbent dosage (1-10 $\left.\mathrm{g} \mathrm{L}^{-1}\right)$ on the removal efficiency was investigated at constant temperature $(300.15 \pm 1 \mathrm{~K})$ and contact time (125 min) with initial acrylic acid concentration $4323 \mathrm{mg} \mathrm{L}^{-1}$. Fig. 5 reveals that the removal efficiency increased with an increase in adsorbent dosage. It is certainly due to more active sites for the adsorption of acrylic acid from an increased amount of $\mathrm{CaO}_{2}$ nanoparticles. A seventy-five percent removal efficiency for $1 \mathrm{~g} \mathrm{~L}^{-1} \mathrm{CaO}_{2}$ nanoparticles was observed, which enhanced with an increase in adsorbent dosage up to $99 \%$ (7 $\mathrm{g} \mathrm{L}^{-1}$ adsorbent dosage). On further increase in adsorbent dosage, the increase in removal efficiency was not considerable. Thus, the optimum $\mathrm{CaO}_{2}$ nanoparticles dosage was found to be $7 \mathrm{~g} \mathrm{~L}^{-1}$. However, due to the limited amount of nanoparticles available, further studies were conducted at $1 \mathrm{~g} \mathrm{~L}^{-1}$ adsorbent dosage. 


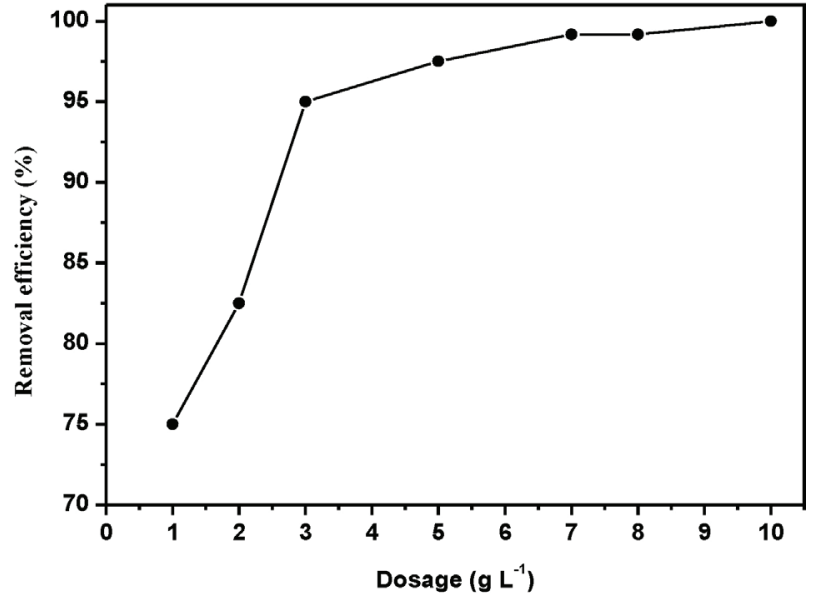

Fig. 5 - Effect of adsorbent dosage on the removal efficiency of acrylic acid onto $\mathrm{CaO}$, nanoparticles (initial acrylic acid concentration $=4323 \mathrm{mg} \mathrm{L}^{-1}$, temperature $=300.15 \mathrm{~K}$, time $=$ $125 \mathrm{~min}$ )

\section{Effect of initial acrylic acid concentration}

The removal efficiency is dependent on the initial acrylic acid concentration as it serves as a principle driving force to overcome all mass transfer resistances of the acrylic acid between aqueous and solid phase. This was studied by varying the acrylic acid concentration at the constant adsorbent dosage $\left(1 \mathrm{~g} \mathrm{~L}^{-1}\right)$, contact time (125 $\left.\mathrm{min}\right)$, and temperature $(300.15 \pm 1 \mathrm{~K})$, as depicted in Fig. 6. As the initial acrylic acid concentration increased from 720 to $7206 \mathrm{mg} \mathrm{L}^{-1}$, the removal efficiency gradually reduced from 99.9 to $50 \%$ until equilibrium was reached. This was almost certainly because of the saturation of available sites for adsorption. However, the adsorption efficiency for the concentrations $1500 \mathrm{mg} \mathrm{L}^{-1}$ and $3000 \mathrm{mg} \mathrm{L}^{-1}$ was observed to be almost the same. This may be attributed to the fact that the difference in concentration was not high enough to bring about a noticeable removal efficiency in this concentration range.

\section{Effect of temperature}

The adsorption of acrylic acid was studied at different temperatures $(300.15$ to $313.15 \mathrm{~K})$ using $\mathrm{CaO}_{2}$ nanoparticles as an adsorbent with initial acrylic acid concentration 2882, 4323, and 5764 $\mathrm{mg} \mathrm{L}^{-1}$. A decrease in removal efficiency with the increase in the solution temperature was observed (Fig. 7), which was attributed to an exothermic adsorption process. This trend could be attributed to the weakening of adsorptive forces between active sites of $\mathrm{CaO}_{2}$ nanoparticles and acrylic acid, as well as between the adjacent molecules of the adsorbed phases. The optimum adsorption temperature of acrylic acid with $\mathrm{CaO}$, nanoparticles was observed at $300.15 \mathrm{~K}$, which will have the benefit of operation at ambient temperature.

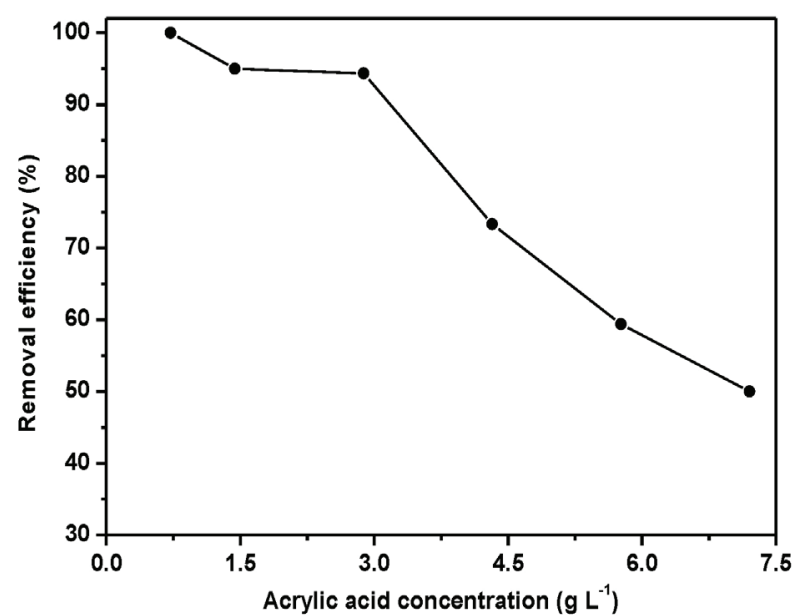

Fig. 6 - Effect of initial concentration on the removal efficiency of acrylic acid onto $\mathrm{CaO}$, nanoparticles (adsorbent dosage $=1 \mathrm{~g} \mathrm{~L}^{-1}$, temperature $=300.15 \mathrm{~K}$, time $=125 \mathrm{~min}$ )

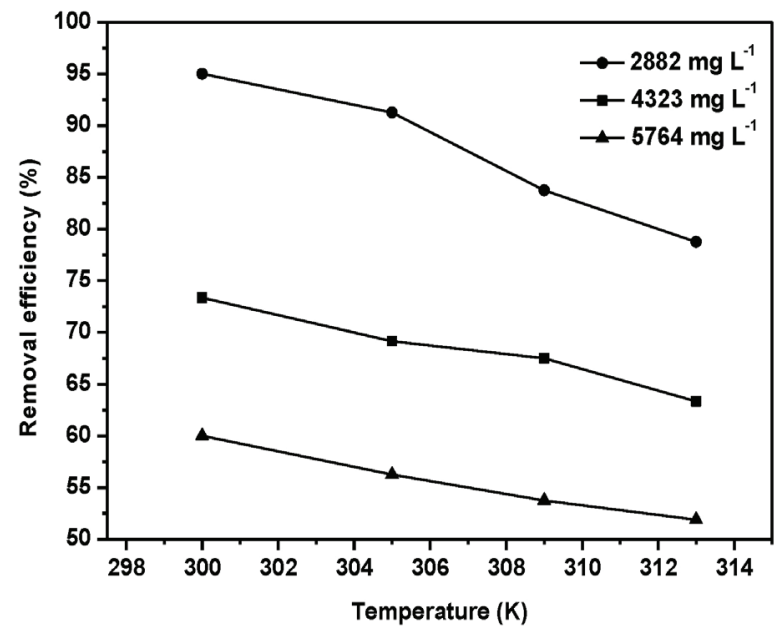

Fig. 7 - Effect of temperature on the removal efficiency of acrylic acid onto $\mathrm{CaO}$, nanoparticles (initial acrylic acid concentration $=2882,4323,5764 \mathrm{mg} \mathrm{L}^{-1}$, adsorbent dosage $=1 \mathrm{~g} \mathrm{~L}^{-1}$, time $=125 \mathrm{~min}$, temperature $=300.15-313.15 \mathrm{~K}$ )

\section{Recovery of acrylic acid after desorption}

The desorption of acrylic acid from the surface of $\mathrm{CaO}_{2}$ nanoparticles was performed to check the economic feasibility. The point study revealed percent desorption of acrylic acid to be $62.4 \%$. During sonication, ultrasonic waves generate vibrations in adsorbent and adsorbate, provoking desorption of the most weakly bound molecules, such as those adsorbed by physic-sorption. However, since most of the acrylic acid is adsorbed by chemisorption, the vibration does not have sufficient energy to break the acid-adsorbent bonds on the surface of $\mathrm{CaO}_{2}$ nanoparticles.

\section{Adsorption isotherms}

In order to describe how acrylic acid molecules will interact with $\mathrm{CaO}_{2}$ nanoparticles, providing a 
panorama of the course taken by the system under study in a concise form, and to optimize the design of an adsorption system to remove acrylic acid from aqueous solution, proper knowledge of adsorption properties and equilibrium data, i.e., adsorption isotherms, is required. To optimize the design of the adsorption system, it is essential to establish the most appropriate correlation for the equilibrium curve. Adsorption equilibrium is established when the amount of acrylic acid adsorbed onto $\mathrm{CaO}_{2}$ nanoparticles in unit time is equal to the amount be- ing desorbed. The equilibrium acrylic acid concentration remains constant, and plotting solid phase concentration against liquid phase concentration graphically depicts the equilibrium adsorption isotherm.

In this study, various two-and three-parameter models, such as Langmuir, Freundlich, Dubinin-Radushkevich, Temkin, Hill, Redlich-Peterson, Sips and Toth models (Table 3) were fitted in their non-linear form to estimate the model parameters. Langmuir isotherm assumes monolayer adsorption,

Table 3 -Expressions of non-linear adsorption isotherm models and the different parameters involved

\begin{tabular}{|c|c|c|}
\hline Isotherm & Non-linear form & Adjustable model parameters and $R^{2}$ \\
\hline Langmuir $^{45}$ & $\begin{array}{ll}q_{\mathrm{e}}= & \frac{Q_{0} b C_{\mathrm{e}}}{1+b C_{\mathrm{e}}} \\
Q_{0} & - \text { maximum monolayer coverage capacities }\left(\mathrm{mg} \mathrm{g}^{-1}\right) \\
b & - \text { Langmuir isotherm constant }\left(\mathrm{dm}^{3} \mathrm{mg}\right)\end{array}$ & $\begin{array}{l}Q_{0}\left(\mathrm{mg} \mathrm{g}^{-1}\right)=3620 \\
b\left(\mathrm{dm}^{3} \mathrm{mg}\right)=0.008171 \\
R^{2}=0.9931\end{array}$ \\
\hline Freundlich ${ }^{46}$ & $\begin{aligned} q_{\mathrm{e}}= & K_{\mathrm{F}} f C_{\mathrm{e}}^{1 / n} \\
K_{\mathrm{F}} & - \text { Freundlich isotherm constant }\left(\mathrm{mg} \mathrm{g}^{-1}\right)\left(\mathrm{dm}^{3} \mathrm{~g}^{-1}\right)^{n} \\
& \text { related to adsorption capacity } \\
n & - \text { adsorption intensity }\end{aligned}$ & $\begin{array}{l}K_{\mathrm{F}}\left(\mathrm{mg} \mathrm{g}^{-1}\right)\left(\mathrm{dm}^{3} \mathrm{~g}^{-1}\right)^{n}=568.1 \\
n=4.33 \\
R^{2}=0.96\end{array}$ \\
\hline Dubinin-Radushkevich $^{47}$ & $\begin{array}{l}q_{\mathrm{e}}=q_{\mathrm{s}} \exp \left(\frac{\left(R T \ln \left(1+1 / C_{\mathrm{e}}\right)\right)^{2}}{-2 E^{2}}\right) \\
q_{s}-\text { theoretical isotherm saturation capacity }\left(\mathrm{mg} \mathrm{g}^{-1}\right) \\
E \quad-\text { energy of adsorption }\left(\mathrm{kJ} \mathrm{mol}^{-1}\right)\end{array}$ & $\begin{array}{l}q_{\mathrm{s}}\left(\mathrm{mg} \mathrm{g}^{-1}\right)=3405 \\
E\left(\mathrm{~kJ} \mathrm{~mol}^{-1}\right)=23.17 \\
R^{2}=0.9719\end{array}$ \\
\hline Temkin $^{48}$ & $\begin{array}{l}q_{\mathrm{e}}=\frac{R T}{b_{\mathrm{T}}} \ln A_{\mathrm{T}} C_{\mathrm{e}} \\
A_{\mathrm{T}}-\text { Temkin isotherm equilibrium binding constant }\left(\mathrm{L} \mathrm{g}^{-1}\right) \\
b_{\mathrm{T}}-\text { Temkin isotherm constant }\end{array}$ & $\begin{array}{l}A_{\mathrm{T}}\left(\mathrm{L} \mathrm{g}^{-1}\right)=0.1556 \\
b_{\mathrm{T}}=3.894 \\
R^{2}=0.9904\end{array}$ \\
\hline Hill $^{49}$ & $\begin{array}{l}q_{\mathrm{e}}=\frac{q_{\mathrm{s}_{\mathrm{H}}} C_{\mathrm{e}}^{n_{\mathrm{H}}}}{K_{D}+C_{\mathrm{e}}^{n_{\mathrm{H}}}} \\
q_{\mathrm{S}_{\mathrm{H}}}-\text { Hill isotherm maximum uptake saturation }\left(\mathrm{mg} \mathrm{L}^{-1}\right) \\
n_{\mathrm{H}}-\text { Hill cooperativity coefficient of the binding interaction }\end{array}$ & $\begin{array}{l}q_{\mathrm{s}_{\mathrm{H}}}\left(\mathrm{mg} \mathrm{L}^{-1}\right)=4027 \\
n_{\mathrm{H}}=0.7048 \\
R^{2}=0.9996\end{array}$ \\
\hline Redlich-Peterson ${ }^{50}$ & $\begin{array}{ll}q_{\mathrm{e}}= & \frac{K_{\mathrm{R}} C_{\mathrm{e}}}{1+a_{\mathrm{R}} C_{\mathrm{e}}^{g}} \\
K_{\mathrm{R}} & - \text { Redlich-Peterson isotherm constant }\left(\mathrm{L} \mathrm{g}^{-1}\right) \\
a_{\mathrm{R}} & - \text { Redlich-Peterson isotherm constant }\left(\mathrm{mg}^{-1}\right) \\
g & - \text { Redlich-Peterson isotherm exponent }\end{array}$ & $\begin{array}{l}K_{\mathrm{R}}\left(\mathrm{L} \mathrm{g}^{-1}\right)=36.87 \\
a_{\mathrm{R}}\left(\mathrm{mg}^{-1}\right)=0.01745 \\
g=0.9318 \\
R^{2}=0.9998\end{array}$ \\
\hline $\operatorname{Sips}^{51}$ & $\begin{array}{l}q_{\mathrm{e}}=\frac{K_{\mathrm{S}} C_{\mathrm{e}}^{\beta_{\mathrm{S}}}}{1+a_{\mathrm{S}} C_{\mathrm{e}}^{\beta_{\mathrm{S}}}} \\
K_{S}-\text { Sips isotherm model constant }\left(\mathrm{L} \mathrm{g}^{-1}\right) \\
a_{\mathrm{S}}-\text { Sips isotherm model constant }\left(\mathrm{L} \mathrm{mg}^{-1}\right) \\
\beta_{\mathrm{S}}-\text { Sips isotherm model exponent }\end{array}$ & $\begin{array}{l}K_{S}\left(\mathrm{~L} \mathrm{~g}^{-1}\right)=101.9 \\
a_{\mathrm{S}}\left(\mathrm{L} \mathrm{mg}^{-1}\right)=0.0253 \\
\beta_{\mathrm{S}}=0.7048 \\
R^{2}=0.9996\end{array}$ \\
\hline Toth $^{50}$ & $\begin{array}{l}q_{\mathrm{e}}=\frac{q_{\mathrm{S}_{T h}} C_{\mathrm{e}}}{\left(K_{T h}+C_{\mathrm{e}}^{T h}\right)^{1 / T h}} \\
q_{\mathrm{S}_{T h}}-\text { Toth theoretical isotherm saturation capacity }\left(\mathrm{mg} \mathrm{g}^{-1}\right) \\
K_{T h}-\text { Toth isotherm model constant }\left(\mathrm{L} \mathrm{g}^{-1}\right) \\
T h \quad-\text { Toth isotherm model exponent }\end{array}$ & $\begin{array}{l}q_{\mathrm{S}_{T h}}\left(\mathrm{mg} \mathrm{g}^{-1}\right)=4107 \\
K_{T h}\left(\mathrm{~L} \mathrm{~g}^{-1}\right)=13.43 \\
T h=0.6155 \\
R^{2}=0.9996\end{array}$ \\
\hline
\end{tabular}




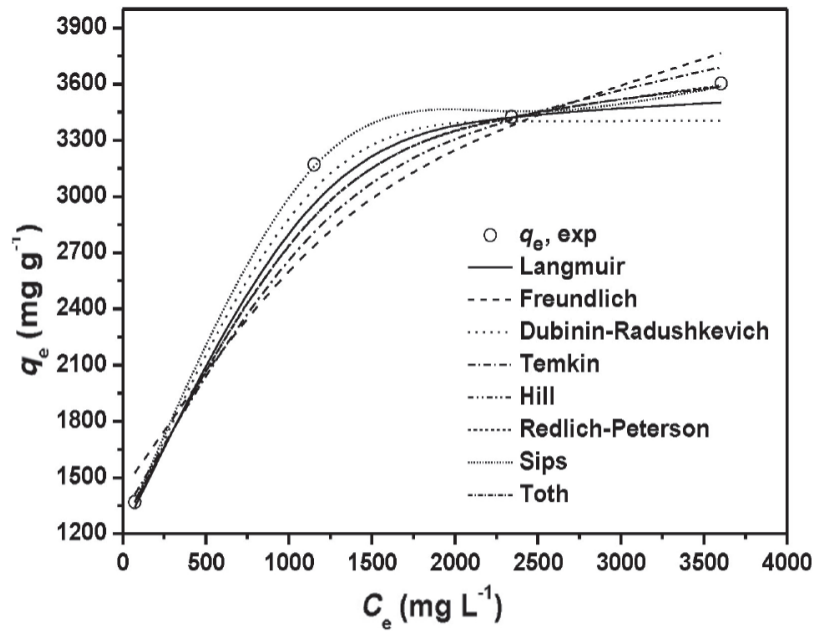

Fig. 8-Comparisons of various non-linear two- and three-parameter adsorption isotherm models used in the study (initial acrylic acid concentration $=4323 \mathrm{mg} \mathrm{L}^{-1}$, adsorbent dosage $=1 \mathrm{~g} \mathrm{~L}^{-1}$, time $=125 \mathrm{~min}$, and temperature $=300.15 \mathrm{~K}$ )

i.e., the adsorbed layer is one molecular in thickness, and with a finite number of identical sites onto a homogeneous surface. ${ }^{45}$ Freundlich isotherm model describes the non-ideal and reversible adsorption and can be applied to multilayer adsorption with non-uniform distribution of adsorption sites and affinities over the heterogeneous surface. ${ }^{46}$ Dubinin-Radushkevich isotherm was conceived to express the adsorption mechanism with Gaussian energy distribution onto a heterogeneous surface. ${ }^{47}$ Temkin isotherm model takes into account adsorbent-adsorbate interactions and assumes that the heat of adsorption of all molecules in the layer would decrease linearly with coverage by ignoring the extremely low and high values of concentrations. ${ }^{48}$ Hill isotherm assumes adsorption to be a cooperative phenomenon to describe the binding of different species onto homogeneous substrate. ${ }^{49}$ Redlich-Peterson isotherm is a hybrid of both Langmuir and Freundlich isotherms and is used to represent adsorption equilibria over a wide concentration range, and can be applied either to the homogeneous or heterogeneous system. ${ }^{50} \mathrm{Sips}$ isotherm model is also a combination of Langmuir and Freundlich's expressions deduced for predicting the heterogeneous adsorption system and overcoming the limitation of increasing adsorbate concentration associated with Freundlich isotherm model. ${ }^{51}$ Toth isotherm model was developed to improve Langmuir isotherm and is useful in describing a heterogeneous adsorption system satisfying both low and high-end boundary of the concentration. ${ }^{50}$ The non-linear regression was performed to obtain the best fit for the models.

To test the best fitting isotherm to the experimental data, the coefficient of determination, $R^{2}$, was used, and all the parameters and $R^{2}$ values are presented in Table 3. Fig. 8 shows the experimental and predicted two-and three-parameter isotherms by a non-linear method for the adsorption of acrylic acid onto $\mathrm{CaO}_{2}$ nanoparticles. The Langmuir, Temkin, and Hill isotherms have almost the same high values of $R^{2}$ as compared to Freundlich and Dubinin-Radushkevich for the two-parameter isotherm. Here, the Langmuir isotherm indicates that uptake occurs on a homogeneous surface by monolayer adsorption and chemisorption behaviour due to the formation of an ionic or covalent bond between adsorbent and adsorbate. Additionally, the values of $n$ for Freundlich isotherm are within the range of $1-10$, suggesting that the acrylic acid could be readily adsorbed onto $\mathrm{CaO}_{2}$ nanoparticles, and that the adsorption was beneficial for acrylic acid. The three-parameter isotherm models give high values of $R^{2}$. The Sips and Toth isotherms have the same values of $R^{2}$. The highest $R^{2}$ value for Redlich-Peterson isotherm suggests the best curve model of given experimental data; since its parameter $g$ is close to one, it is in accordance with the low concentration limit of Langmuir isotherm model. The isotherm models fitted the experimental data in the order of Redlich-Peterson $>$ Sips, Toth and Hill $>$ Langmuir $>$ Temkin $>$ Dubinin-Radushkevich $>$ Freundlich.

\section{Adsorption kinetics}

Adsorption kinetics describes the rate of adsorption and the solute uptake rate, which in turn controls the residence time and hence the size of adsorption equipment. In order to deduce the adsorption mechanism of acrylic acid onto $\mathrm{CaO}_{2}$ nanoparticles, pseudo-first-order and pseudo-second-order models were used for three different acrylic acid concentrations (2882, 4323, and 5764 $\mathrm{mg} \mathrm{L}^{-1}$ ) at the temperature of $300.15 \mathrm{~K}$. Pseudo-first-order model explains the adsorption between solid and liquid system based on the physisorption capacity of the solid, and pseudo-second-order model usually describes the experimental data for the chemisorption case. ${ }^{29}$ The non-linear forms of the two models are summarised in Table 4, which were solved using a non-linear regression technique.

The pseudo-first-order and pseudo-second-order kinetic models were fitted to the experimental data (Fig. 9 and Fig. 10) to predict the adsorption kinetics of acrylic acid onto $\mathrm{CaO}_{2}$ nanoparticles. The pseudo-first-order rate constant $k_{1}$, pseudo-second-order rate constant $k_{2}$, experimental equilibrium adsorption capacities $q_{\text {e,exp }}$, calculated equilibrium adsorption capacities $q_{\mathrm{e}, \mathrm{cal}}$, and the coefficient of determination $R^{2}$ are all given in Table 5. The $q_{\mathrm{e}, \mathrm{cal}}$ values calculated from pseudo-first-order kinetic mod- 


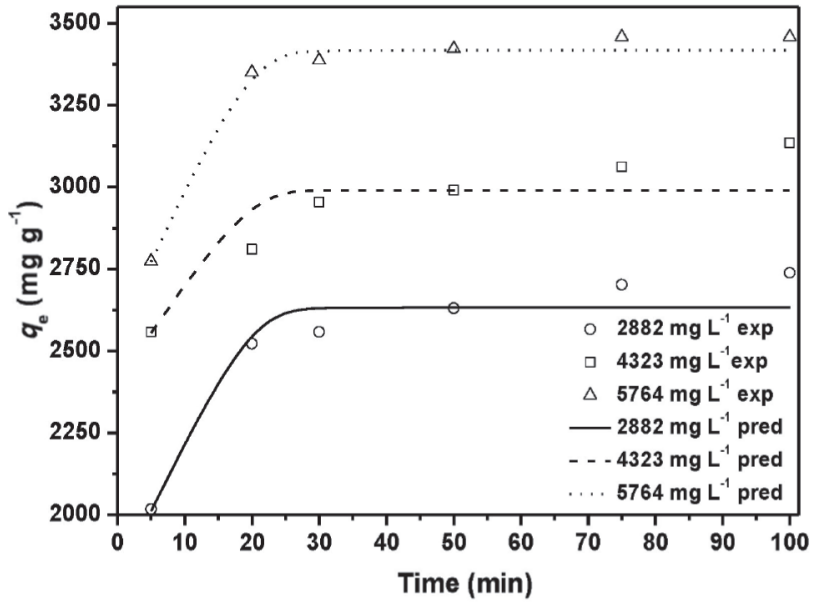

Fig. 9 - Pseudo-first-order kinetic fit for adsorption of acrylic acid onto $\mathrm{CaO}$ nanoparticles (initial acrylic acid concentration $=2882,4323,5764 \mathrm{mg} \mathrm{L}^{-1}$, adsorbent dosage $=1 \mathrm{~g} \mathrm{~L}^{-1}$, time $=125 \mathrm{~min}$, and temperature $=300.15 \mathrm{~K}$ )

Table 4-Non-linear forms of kinetic models used in the present study for the adsorption of acrylic acid onto $\mathrm{CaO}_{2}$ nanoparticles

\begin{tabular}{|c|c|c|c|}
\hline Model & Non-linear form & Plot & Parameters \\
\hline \multirow{5}{*}{$\begin{array}{l}\text { Pseudo- } \\
\text { first- } \\
\text { order }\end{array}$} & $q_{t}=q_{\mathrm{e}}\left(1-\exp ^{-k_{1} t}\right)$ & \multirow[t]{5}{*}{$q_{t}$ vs. $t$} & \multirow[t]{5}{*}{$k_{1}, q_{\mathrm{e}}$} \\
\hline & $\begin{array}{c}q_{t}-\text { amount of adsorbate at } \\
\text { time } t\left(\mathrm{mg} \mathrm{g}^{-1}\right)\end{array}$ & & \\
\hline & 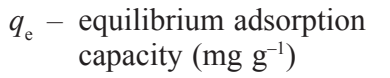 & & \\
\hline & $\begin{aligned} k_{1}- & \text { rate constant of pseudo- } \\
& \text { first-order kinetics } \\
& \left(\mathrm{min}^{-1}\right)\end{aligned}$ & & \\
\hline & $t-$ time $(\min )$ & & \\
\hline
\end{tabular}

$\begin{array}{ll}\begin{array}{l}\text { Pseudo- } \\ \text { second- } \\ \text { order }\end{array} & q_{t}=\frac{k_{2} q_{\mathrm{e}}^{2} t}{1+k_{2} q_{\mathrm{e}} t} \\ k_{2}- & \begin{array}{l}\text { rate constant of pseudo- } t \quad k_{2}, q_{\mathrm{e}}, h \\ \text { second-order kinetics } \\ \left(\mathrm{mg} \mathrm{mg}^{-1} \mathrm{~min}^{-1}\right)\end{array} \\ h= & k_{2} q_{\mathrm{e}}^{2} \\ h- & \begin{array}{l}\text { initial adsorption rate } \\ \quad\left(\mathrm{mg} \mathrm{mg}^{-1} \mathrm{~min}^{-1}\right)\end{array}\end{array}$

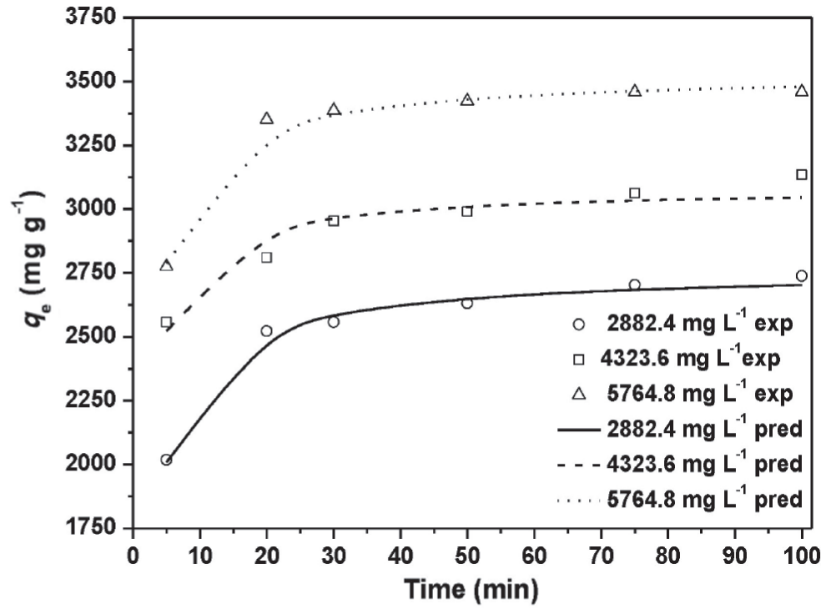

Fig. 10 - Pseudo-second-order kinetic fit for adsorption of acrylic acid onto $\mathrm{CaO}$, nanoparticles (initial acrylic acid concentration $=2882,4323,5764 \mathrm{mg} \mathrm{L}^{-1}$, adsorbent dosage $=1 \mathrm{~g} \mathrm{~L}^{-1}$, time $=125 \mathrm{~min}$, and temperature $=300.15 \mathrm{~K}$ )

el differed appreciably from the experimental values $q_{\text {e,exp }}$, but the $q_{\mathrm{e}, \text { al }}$ values calculated from the pseudosecond-order kinetic model are very close to $q_{\mathrm{e}, \mathrm{exp}}$ values. Moreover, on comparing the values of $R^{2}$, pseudo-second-order kinetic model yielded better results as compared to pseudo-first-order as the values are much closer to unity. Therefore, the adsorption data were well represented by pseudo-second-order kinetics, suggesting that the rate-limiting step of acrylic acid adsorption onto $\mathrm{CaO}_{2}$ nanoparticles is controlled by chemisorption behaviour. ${ }^{52}$

\section{Conclusions}

The characteristics and mechanism of acrylic acid adsorption onto $\mathrm{CaO}_{2}$ nanoparticles is reported in the present study. $\mathrm{CaO}_{2}$ nanoparticles were synthesised and characterised using XRD and FTIR to confirm its formation. The batch adsorption test revealed that the recovery of acrylic acid increased with contact time and adsorbent dosage, and decreased with increase in initial acrylic acid concentration and temperature. The removal efficiency of acrylic acid at concentration $720 \mathrm{mg} \mathrm{L}^{-1}$ was as high as $99 \%$ with $\mathrm{CaO}_{2}$ nanoparticle dosage $1 \mathrm{~g} \mathrm{~L}^{-1}$ and

Table 5 -Comparisons of the kinetic models adsorption rate constants, initial adsorption rate, and calculated and experimental $q_{\mathrm{e}}$ values obtained at different acrylic acid concentrations

\begin{tabular}{|c|c|c|c|c|c|c|c|c|}
\hline \multirow[b]{2}{*}{$\begin{array}{l}\text { Initial conc. } \\
\left(\mathrm{mg} \mathrm{L}^{-1}\right)\end{array}$} & \multirow[b]{2}{*}{$\begin{array}{c}q_{\mathrm{e}, \exp } \\
\left(\mathrm{mg} \mathrm{g}^{-1}\right)\end{array}$} & \multicolumn{3}{|c|}{ Pseudo-first-order kinetic model } & \multicolumn{4}{|c|}{ Pseudo-second-order kinetic model } \\
\hline & & $\begin{array}{c}k_{1} \\
\left(\min ^{-1}\right)\end{array}$ & $\begin{array}{c}q_{\mathrm{e}, \mathrm{cal}} \\
\left(\mathrm{mg} \mathrm{g}^{-1}\right)\end{array}$ & $R^{2}$ & $\begin{array}{c}k_{2} \cdot 10^{-4} \\
\left(\mathrm{mg} \mathrm{mg}^{-1} \min ^{-1}\right)\end{array}$ & $\begin{array}{c}q_{\mathrm{e}, \mathrm{cal}} \\
\left(\mathrm{mg} \mathrm{g}^{-1}\right)\end{array}$ & $\begin{array}{c}h \\
\left(\mathrm{mg} \mathrm{mg}^{-1} \min ^{-1}\right)\end{array}$ & $R^{2}$ \\
\hline 2882 & 2738.28 & 0.28 & 2633 & 0.91 & 1.96 & 2753 & 1487 & 0.99 \\
\hline 4323 & 3170.64 & 0.38 & 2991 & 0.72 & 2.14 & 3080 & 2031 & 0.90 \\
\hline 5764 & 3494.91 & 0.33 & 3417 & 0.98 & 2.94 & 3526 & 2085 & 0.99 \\
\hline
\end{tabular}


contact time 125 minutes. The adsorption of acrylic acid onto $\mathrm{CaO}_{2}$ nanoparticles follows a pseudo-second-order kinetics, and Redlich-Peterson model was the best-fitted isotherm. The percent desorption of acrylic acid from the surface of $\mathrm{CaO}_{2}$ nanoparticles was found to be $64.4 \%$. The results indicated that $\mathrm{CaO}_{2}$ nanoparticles are a promising and potential candidate for the recovery of acrylic acid from aqueous system.

\section{References}

1. Straathof, A. J. J., Sie, S., Franco, T. T., Van der Wielen, L. A. M., Feasibility of acrylic acid production by fermentation, Appl. Microbiol. Biotechnol. 67 (2005) 727. doi: https://doi.org/10.1007/s00253-005-1942-1

2. Jones, T., Dunwoodie, M., Boucher-Ferte, V., Reiff, O., Chemicals for Beginners: The $\mathrm{V}^{\text {th }}$ Edition, (2011) 269.

3. Keshav, A., Chand, S., Wasewar, K. L., Reactive extraction of acrylic acid using tri-n-butyl phosphate in different diluents, J. Chem. Eng. Data 54 (2009) 1782. doi: https://doi.org/10.1021/je800856e

4. Xiaobo, X., Jianping, L., Peilin, C., Advances in the research and development of acrylic acid production from biomass, Chin. J. Chem. Eng. 14 (2006) 419. doi: https://doi.org/10.1016/S1004-9541(06)60094-3

5. Keshav, A., Wasewar, K. L., Chand, S., Uslu, H., Effect of binary extractants and modifier-diluents systems on equilibria of propionic acid extraction, Fluid Phase Equilib. 275 (2009) 21 doi: https://doi.org/10.1016/j.fluid.2008.09.012

6. Keshav, A., Wasewar, K. L., Chand, S., Recovery of propionic acid from an aqueous stream by reactive extraction: effect of diluents, Desalin. 244 (2009) 12. doi: https://doi.org/10.1016/j.desal.2008.04.032

7. Choi, J. I., Hong, W. H., Recovery of lactic acid by batch distillation with chemical reactions using ion exchange resin, J. Chem. Eng. of Jpn. 32 (1999) 184. doi: https://doi.org/10.1252/jcej.32.184

8. Kuila, S. B., Ray, S. K., Dehydration of acetic acid by pervaporation using filled IPN membranes, Sep. Purif. Tech. 81 (2011) 295. doi: https://doi.org/10.1016/j.seppur.2011.07.033

9. Mahajan, Y. S., Shah, A. K., Kamath, R. S., Salve, N. B., Mahajani, S. M., Recovery of trifluoroacetic acid from dilute aqueous solutions by reactive distillation, Sep. Puri. Tech. 59 (2008) 58. doi: https://doi.org/10.1016/j.seppur.2007.05.027

10. Dhongde, V., Wasewar, K. L., De, B. S., Development of nanohybrid adsorbent for defluoridation from aqueous systems, Chemosphere 188 (2017) 354. doi: https://doi.org/10.1016/j.chemosphere.2017.08.153

11. Singh, K., Lataye, D. H., Wasewar, K. L., Removal of fluoride from aqueous solution by using bael (Aegle marmelos) shell activated carbon: Kinetic, equilibrium and thermodynamic study, J. Fluo. Chem. 194 (2017) 23. doi: https://doi.org/10.1016/j.jfluchem.2016.12.009

12. Singh, K., Lataye, D. H., Wasewar, K. L., Removal of fluoride from aqueous solution by using low-cost sugarcane bagasse: Kinetic study and equilibrium isotherm analysis, J. Haz. Tox. Rad. Waste 3 (2016) 1. doi: https://doi.org/10.1061/(ASCE)HZ.2153-5515.0000309
13. Singh, K., Lataye, D. H., Wasewar, K. L., Adsorption of fluoride onto sugarcane bagasse: An application of Taguchi's design of experimental methodology, J. Ind. Wat. Works Ass. 1 (2015) 285.

14. Singh, K., Lataye, D. H., Wasewar, K. L., Yoo, C. K., Removal of fluoride from aqueous solution: status and techniques, Desal. Water Treat. 51 (2013) 3233. doi: https://doi.org/10.1080/19443994.2012.749036

15. Kumar, P., Rao, R., Chand, S., Kumar, S., Wasewar, K. L., Yoo, C. K., Adsorption of lead from aqueous solution onto coir-pith activated carbon, Desal. Water Treat. 51 (2013) 2529. doi: https://doi.org/10.1080/19443994.2012.749009

16. Kumar, P., Agnihotri, R., Wasewar, K. L., Uslu, H., Yoo, C. $K$., Status of adsorptive removal of dye from textile industry effluent, Desal. Water Treat. 50 (2012) 226. doi: https://doi.org/10.1080/19443994.2012.719472

17. Gulipalli, C. S., Prasad, B., Wasewar, K. L., Batch study, equilibrium, kinetics of adsorption of selenium using rice husk ash (RHA), J. Eng. Sci. Tech. 6 (2011) 590.

18. Kumar, P., Chand, S., Padmini, B. N., Teng, T. T., Wasewar, $K$. $L$., Adsorption of cadmium ions from aqueous solution using granular activated carbon and activated clay, CLEAN: Soil Air Water 38 (2010) 49.

19. Wasewar, K. L., Adsorption of metals onto tea factory waste: A review, Int. J. Res. Rev. App. Sci. 3 (2010) 303.

20. Gulipalli, C. S., Prasad, B., Wasewar, K. L., Removal of selenium by adsorption onto granular activated carbon (GAC) and powdered activated carbon (PAC), CLEAN 37 (2009) 872.

21. Gulipalli, C. S., Prasad, B., Wasewar, K. L., Adsorption of selenium using bagasse fly ash (BFA) CLEAN 37 (2009) 534.

22. Kumar, S., Prasad, B., Wasewar, K. L., Adsorption of tin using granular activated carbon, J. Env. Prot. Sci. 3 (2009) 41.

23. Atif, M., Prasad, B., Wasewar, K. L., Mishra, I. M., Batch Adsorption of $\mathrm{Zn}$ using tea factory waste as an adsorbent, Desalination 244 (2009) 66. doi: https://doi.org/10.1016/j.desal.2008.04.036

24. Atif, M., Prasad, B., Wasewar, K. L., Characterization of factory tea waste as an adsorbent for removal of heavy metals, J. Fut. Eng. Tech. 3 (2008) 47.

25. Rajoriya, R. K., Prasad, B., Mishra, I. M., Wasewar, K. L., Adsorption of benzaldehyde on granular activated carbon: Kinetics, equilibrium, and thermodynamic, Chem. Biochem. Eng. 22 (2007) 219.

26. Wasewar, K. L., Ravichandra, Y., Kumar, A. M., Godbole, $V$., Adsorption mechanism for the adsorption of heavy metals using tea waste as an adsorbent, J. Future Eng. Tech. 3 (2006) 41.

27. Aşç, Y. S., Hasdemir, I. M., Removal of some carboxylic acids from aqueous solutions by hydrogels, J. Chem. Eng. Data 53 (2008) 2351.

doi: https://doi.org/10.1021/je800230t

28. Uslu, H., Inci, I., Bayazit, S. S., Adsorption equilibrium data for acetic acid and glycolic acid onto Amberlite IRA67, J. Chem. Eng. Data 55 (2010) 1295. doi: https://doi.org/10.1021/je900635z

29. Madan, S. S., Wasewar, K. L., Kumar, C. R., Adsorption kinetics, thermodynamics, and equilibrium of $\alpha$-toluic acid onto calcium peroxide nanoparticles, Ad. Pow. Tech. 27 (2016) 2112. doi: https://doi.org/10.1016/j.apt.2016.07.024 
30. Roncaroli, F., Blesa, M. A., Kinetics of adsorption of carboxylic acids onto titanium dioxide, Phys. Chem. Chem. Phys. 12 (2010) 9938. doi: https://doi.org/10.1039/c003086d

31. López-Velandia, C., Moreno-Barbosa, J. J., Sierra-Ramirez, R., Giraldo, L., Moreno-Piraján, J. C., Adsorption of volatile carboxylic acids on activated carbon synthesized from watermelon shells, Adsorpt. Sci. Technol. 32 (2014) 227. doi: https://doi.org/10.1260/0263-6174.32.2-3.227

32. Tong, S. R., Wu, L. Y., Ge, M. F., Wang, W. G., Pu, Z. F., Heterogeneous chemistry of monocarboxylic acids on $\alpha-\mathrm{Al}_{2} \mathrm{O}_{3}$ at different relative humidities, Atmos. Chem. Phys. 10 (2010) 7561. doi: https://doi.org/10.5194/acp-10-7561-2010

33. Madan, S. S., Wasewar, K. L., Kumar, C. R., Optimization of adsorptive removal of $\alpha$-toluic acid by $\mathrm{CaO}_{2}$ nanoparticles using response surface methodology, Res. Eff. Tech. 3 (2017) 88 .

34. Madan, S. S., Wasewar, K. L., Pandharipande, S. L., Modeling the adsorption of benzeneacetic acid on $\mathrm{CaO}_{2}$ nanoparticles using artificial neural network, Res. Eff. Tech. 2 (2016) 53. doi: https://doi.org/10.1016/j.reffit.2016.10.004

35. Madan, S. S., Wasewar, K. L., Pandharipande, S. L., Artificial Neural Network (ANN) method for modeling of benzeneacetic acid adsorption using $\mathrm{CaO}_{2}$ nanoparticles, Sep. Tech. Chem. Biochem. Petro. Env. Eng. 10 (2016).

36. Waghmare, M. D., Wasewar, K. L., Sonawane, S. S., Kinetics and thermodynamics of picolinic acid adsorption on low cost adsorbent peanut hull, Res. J. Chem. Env. 18 (2014) 87.

37. Hochella, M. F., Madden, A. S., Earth's nano-compartment for toxic metals, Elements 1 (2005) 199. doi: https://doi.org/10.2113/gselements.1.4.199

38. Baillieul, H., Moor, G. D., Leys, W., Geert, K. V., Burdick, $J$., Gevaerts, $W$., Enhanced bioremediation of a BTEX contaminated soil in Belgium. IXPER $\mathrm{Ca} \mathrm{H}_{2} \mathrm{O}_{2}$ RemidiationArcadis-236820.pdf.

39. Park, J. W., Park, B. K., Kim, J. E., Remediation of soil contaminated with 2,4-dichlorophenol by treatment of minced shepherd's purse roots, Arch. Env. Contamin. Tox. 50 (2006) 191. doi: https://doi.org/10.1007/s00244-004-0119-8

40. Northup, A., Cassidy, D., Calcium peroxide $\left(\mathrm{CaO}_{2}\right)$ for use in modified Fenton chemistry, J. Hazard. Mat. 152 (2008) 1164. doi: https://doi.org/10.1016/j.jhazmat.2007.07.096

41. Madan, S. S., Upwanshi, W. A., Wasewar, K. L., Adsorption of $\alpha$-toluic acid by calcium peroxide nanoparticles, Desalin. Water Treat. 57 (2016) 16507.

doi: https://doi.org/10.1080/19443994.2015.1079255

42. Olyaie, E., Banejad, H., Afkhami, A., Rahmani, A., Khodaveisi, J., Development of a cost-effective technique to remove the arsenic contamination from aqueous solutions by calcium peroxide nanoparticles, Sep. Puri. Tech. 95 (2012) 10.

43. Andrews, L., Chertihin, G. V., Thompson, C. A., Dillon, J., Byrne, S., Bauschlicher, C. W., Infrared spectra and quantum chemical calculations of group $2 \mathrm{MO}_{2}, \mathrm{O}_{2} \mathrm{MO}_{2}$, and related molecules, The J. Phy. Chem. 100 (1996) 100. doi: https://doi.org/10.1021/jp9519934

44. Umemura, J., Hayashi, S., Infrared spectra and molecular configurations of liquid and crystalline acrylic acid, Bull. Inst. Chem. Res., Kyoto Univ. 52 (1974) 585.

45. Langmuir, I., The constitution and fundamental properties of solids and liquids, J. The Am. Chem. Soc. 38 (1916) 2221 . doi: https://doi.org/10.1021/ja02268a002

46. Freundlich, U., Die adsorption in lusungen, J. Phy. Chem. 57 (1906) 385.

47. Dabrowski, A., Adsorption from theory to practice, Adv. Coll. Inter. Sci. 93 (2001) 135. doi: https://doi.org/10.1016/S0001-8686(00)00082-8

48. Tempkin, M. I., Pyzhev, V., Kinetics of ammonia synthesis on promoted iron catalyst, ActaPhys. Chim. USSR 12 (1940) 327.

49. Hill, A. V., The possible effects of the aggregation of the molecules of haemoglobin on its dissociation curves, J. Physiol. 40 (1910) 4.

50. Koopal, L. K., Van, Riemsdijk, W. H., De-Wit, J. C., Benedetti, M. F., Analytical isotherm equations for multicomponent adsorption to heterogeneous surfaces, J. Coll. Inter. Sci. 166 (1994) 51. doi: https://doi.org/10.1006/jcis.1994.1270

51. Sips, R., On the structure of a catalyst surface, The J. Chem. Phy. 16 (1948) 490. doi: https://doi.org/10.1063/1.1746922

52. Xiong, L., Yang, Y., Mai, J., Sun, W., Zhang, C., Wei, D., Chen, Q., Ni, J., Adsorption behavior of methylene blue onto titanate nanotubes, C. Eng. J. 156 (2010) 313. doi: https://doi.org/10.1016/j.cej.2009.10.023 